\title{
PREMATURE LOSS OF DECIDUOUS TEETH
}

\author{
BY \\ R. S. ILLINGWORTH and J. H. GARDINER \\ From the Department of Child Health and the Department of Dental Surgery, \\ the University of Sheffield
}

(RECEIVED FOR PUBLICATION APRIL 25, 1955)

Premature exfoliation of deciduous teeth is very rare in children. It is well known that it may occur in severe pink disease (acrodynia) and in local disease of bone, such as osteitis and eosinophilic granuloma (Thoma, 1937; Stones, 1954). The teeth in the above conditions are extruded with the roots intact due to a loss of their supporting bony tissue. In hereditary ectodermal dysplasia teeth are badly formed or lacking.

An extensive search of the literature, including all volumes of the Quarterly Cumulative Index Medicus, has failed to reveal more than two references to premature loss of deciduous teeth due to a cause other than the above. Sobel, Clark, Fox and Robinow (1953) described a child with genu valgum and premature loss of teeth. She was first seen at the age of 19 months. Six weeks previously several teeth had become loose and all had been shed before her first attendance at hospital. Her serum calcium and phosphorus levels were normal, but her serum alkaline phosphatase was low (0.9 to 1.64 BesseyLowry units). Biopsy of the liver and ribs showed a deficiency of phosphatase. Examination of the bone (by Dr. Edwards Park) showed a picture indistinguishable from that of rickets. There was no history of poisoning by beryllium, which interferes with phosphatase activity, or by fluoride. Radiographs of her limbs were thought to show an osteodystrophy. The tibiae were bowed, and there was cortical new bone formation, with irregular calcification in the metaphyses. The father's alkaline phosphatase was abnormally low, suggesting that the condition was of genetic origin. Treatment with 500,000 units of vitamin $D$ for 10 days had no effect on the enzyme activity. The writers suggested that growing bone requires the presence of alkaline phosphatase for normal calcification, and that the skeletal disorder may be related to an abnormality in the quantity of phosphatase in the tissues.

This patient has been described by Sobel elsewhere, and Clausen (1952), in discussing the case, said that he had seen three similar children in one family.

Rathbun (1948) had previously described a case of osteodystrophy with a virtual absence of serum alkaline phosphatase, the figures ranging from 0 to 0.7 Bessey-Lowry units, but the child died before teeth erupted. Luder (1954) described a similar child, but in his case the serum calcium was high (14.8 mg. per $100 \mathrm{ml}$.) and the blood urea was raised (50-80 mg. per $100 \mathrm{ml}$.). The teeth (personal communication) were unaffected.

Below is the case history of a child with premature loss of deciduous teeth. He was referred to the Children's Hospital, Sheffield, by Dr. J. H. D. Millar of Scunthorpe.

\section{Case History}

The boy was first seen at the age of 2 years and 5 months, because his teeth were falling out and he had genu valgum. He was an only child, weighing $28 \mathrm{lb}$. His birth weight was $9 \mathrm{lb}$. His mother was well during pregnancy, and had had a good diet.

The boy was breast fed for the first week, then had National dried milk for two months, and finally 'ostermilk No. 2', until at 4 months he was given thickened feeds. He was given 20 drops of 'adexolin' daily from the age of 5 months. At 6 months he was given solids, and thereafter took a good diet, including adequate quantities of meat, eggs, fish and milk.

His development was normal. He sat without support at 6 months, walked without support at 11 months, said single words with meaning before his first birthday and put many words together before he was 2. Physically the boy was well, apart from the two symptoms for which he was referred to us. He was full of energy, happy and free from lassitude. The genu valgum was noted at the age of $\mathbf{2 0}$ months. There were no previous illnesses.

The two first lower incisors erupted at 3 months of age, and two more appeared in the ensuing two months, but they all became loose one to two weeks after their eruption. By the age of 5 months two of the lower deciduous incisors had exfoliated. During the following two and a half years, 11 further deciduous teeth were shed, until 


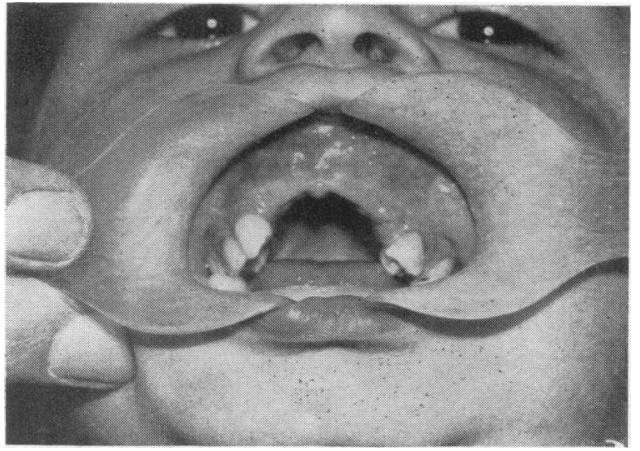

Fig. 1.-View of the patient's upper teeth showing the narrow, high-vaulted palate.

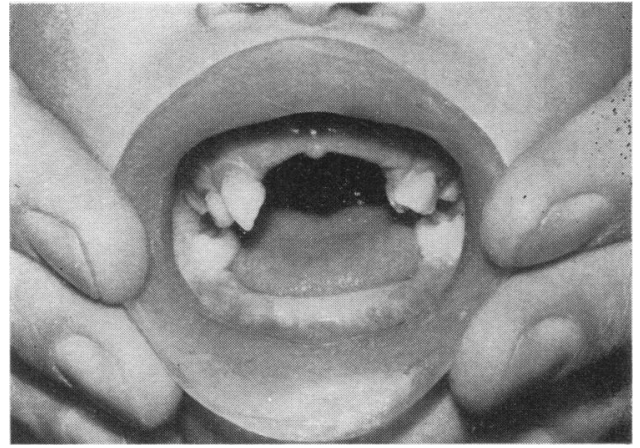

FIG. 2.-Patient's dentition at 3 years of age after shedding 13 deciduous (milk) teeth.

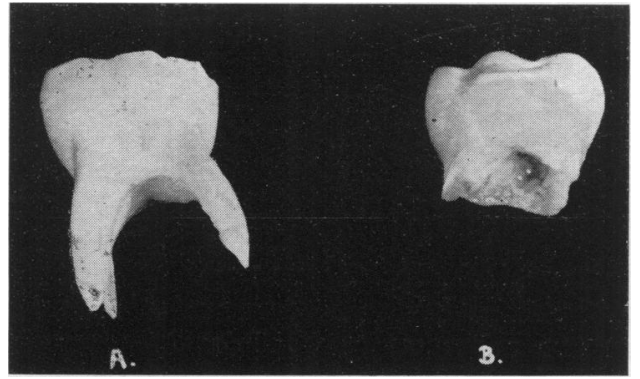

Fig. 3.-Patient's lower deciduous molar (B) showing complete absorption of the roots. As a comparison (A) is a similar molar from a normal child of about the same age.
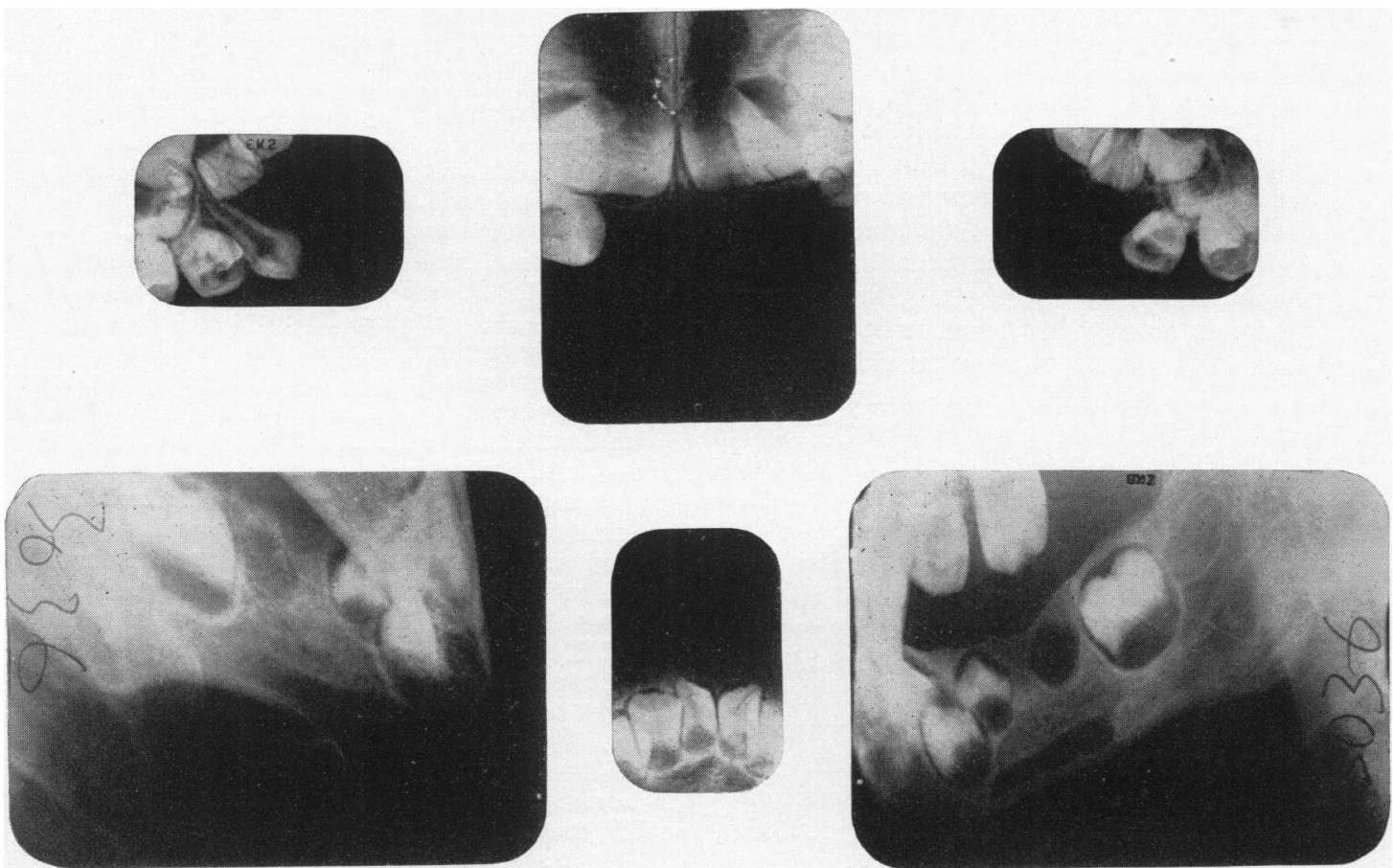

FIG. 4.-Radiographs taken at $3 \frac{1}{2}$ years of age showing the developing permanent teeth of this patient. 
at the age of 3 years he had only seven deciduous teeth in his mouth (Fig. 2).

There was no family history of bone deformity or of abnormality of teeth.

On examination he was a healthy-looking boy. Apart from his mouth and knees there were no abnormal physical signs. The hair, finger nails and skin were normal. When the knees were placed together in the supine position, the internal malleoli were $1 \frac{1}{2}$ in. apart.

Examination of the mouth showed a narrow upper

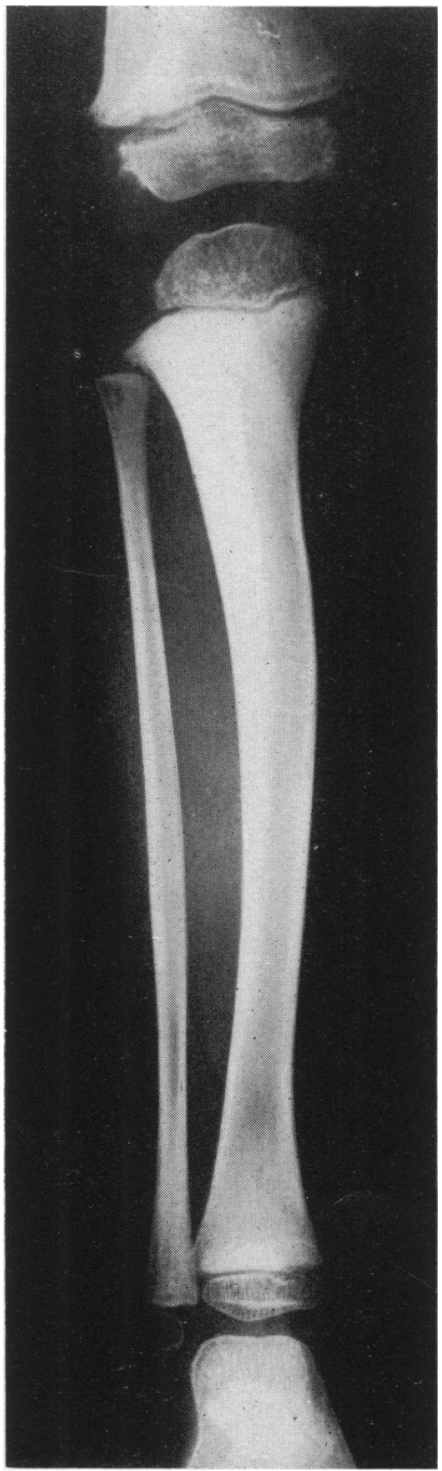

FIG. 5. $-X$-ray photograph of tibia, showing bowing, tilting of the upper metaphysis, and a triangular area of sclerosis at the upper end of the diaphysis, mainly on the fibular side. dental arch with a high vaulted palate (Fig. 1). The gums were normal. The remaining teeth were normal in appearance and free from caries.

Upon examining a lower deciduous molar immediately after exfoliation the macroscopic appearance (Fig. 3) was similar to that of a deciduous molar normally shed at 10 years of age. Histological examination, however, of another of the lower second deciduous molars showed incomplete formation (corresponding to an age of about 1 year), with slight evidence of resorption. Radiological examination (Fig. 4) showed that the permanent teeth were present.

Other investigations showed that the urine was normal chemically and microscopically.

The Wassermann reaction was negative. The blood group was $\mathrm{O} R \mathrm{Rh}(\mathrm{D})$ positive.

The serum calcium, phosphorus and alkaline phosphatase levels were as follows:

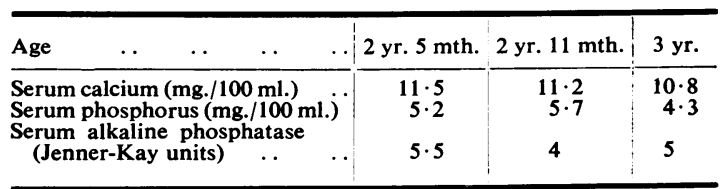

The serum albumin was $3.6 \mathrm{~g}$. per $100 \mathrm{ml}$. and serum globulin $2 \cdot 5 \mathrm{~g}$. per $100 \mathrm{ml}$.

$X$-ray studies of the skeleton at the age of 4 years showed bowing of the tibia on both sides (Fig. 5) with a bone sclerosis occupying a triangular area in the upper end of the diaphyses mainly on the fibular side. The upper metaphysis of the tibia was tilted. Similar changes, though less marked, were present in other long bones. There was general osteoporosis of the pelvis.

\section{Discussion}

The $x$-ray photographs of the tibia reproduced in the paper by Sobel et al. (1953) are indistinguishable from the $x$-ray picture in our patient, but they correspond exactly with those reproduced in a paper by Holt, Latourette and Watson (1954) concerning bowing of the legs in normal children, and regarded by them as normal. These authors regard the excessive medial calcification in the upper end of the tibia as secondary to the bowing. In their cases the bowing righted itself, so that the $x$-ray appearances were 'normal' by the age of 4 . (The $x$-ray photographs of our case were taken at the age of 4.) It is not certain, therefore, whether our case should be regarded as having an osteodystrophy or not. There certainly appeared to be some degree of osteoporosis in the skeleton, but osteoporosis is difficult to assess.

The serum alkaline phosphatase level was consistently low in our case, but not as low as that described by other authors to whom reference has been made. Nevertheless, the similarity of our case 
to that of Sobel et al. (1953) is so striking that it seems likely that the condition was the same.

It may be that the incomplete formation and premature absorption of the roots of the teeth was in some way associated with abnormal phosphatase activity. We have no other theory to offer.

\section{Summary}

We have described a boy aged 4 years who exhibited premature shedding of deciduous teeth. At 3 years of age he had only seven deciduous teeth remaining. It was shown that there had been incomplete formation and some premature absorption of the roots.

There was a genu valgum and doubtful radio- logical evidence of an osteodystrophy. The only abnormal biochemical finding was a low serum alkaline phosphatase level.

We wish to thank Dr. J. H. D. Millar of Scunthorpe for referring the patient to us; Dr. T. Lodge for the $x$-ray reports; Miss E. Finch, M.Sc., for the biochemical investigations; and the Photographic Department of the United Sheffield Hospitals for the photographs.

\section{REFERENCES}

Clausen, S. W. (1952). Amer. J. Dis. Child., 83, 411.

Holt, J. F., Latourette, H. B. and Watson, E. H. (1954). J. Amer. med. Ass., 154, 390.

Luder, J. (1954), Proc. roy. Soc. Med., 47, 541.

Rathbun, J. C. (1948). Amer. J. Dis. Çhild., 75, 822

Sobel, E. H., Clark, L. C., Fox, R. P. and Robinow, M. (1953) Pediatrics, 11, 309.

Stones, H. H. (1954). Oral and Dental Diseases, 3rd ed. Edinburgh. Thoma, K. H. (1937). Harv. dent. Rec., 11 (Jan.), p. 35. 